\title{
Sensitization profiles to purified plant food allergens among pediatric patients with allergy to banana
}

\author{
Arantxa Palacin', Santiago Quirce ${ }^{2,3}$, Rosa Sanchez-Monge ${ }^{1}$, Irina Bobolea ${ }^{2}$, Araceli Diaz-Perales ${ }^{1}$, \\ Flora Martin-Muñoz ${ }^{2}$, Cristina Pascual ${ }^{2} \&$ Gabriel Salcedo ${ }^{1}$ \\ 'Unidad de Bioquimica, Departamento de Biotecnologia, E.T.S. Ingenieros Agrónomos, Universidad Politécnica, Madrid, Spain: ${ }^{2}$ Servicio de \\ Alergia, IdiPAZ, Hospital Universitario La Paz, Madrid, Spain: ${ }^{3}$ CIBER de Enfermedades Respiratorias (CIBERES), Madrid, Spain
}

Keywords

banana; food allergy; thaumatin-like protein;

b-1,3-glucanase; lipid transfer protein;

glycosylation.

\begin{abstract}
Banana fruit allergy is well known, but neither immunoglobulin $E$ recognition patterns to purified plant food allergens nor true prevalences of putative banana allergens have been established. This study aimed to characterize b-1,3-glucanase and thaumatin-like protein (TLP) as banana allergens, testing them, together with other plant food allergens, in 51 children with allergic reactions after banana ingestion and both positive specific $\lg E$ and skin prick test (SPT) to banana. Banana b-1,3-glucanase and TLP were isolated and characterized. Both banana allergens, together with kiwifruit TLP Act d 2, avocado class I chitinase Pers a 1, palm pollen profilin Pho d 2 and peach fruit lipid transfer protein (LTP) Pru p 3, were tested by in vitro and in vivo assays. Banana b-1,3-glucanase (Mus a 5) was glycosylated, whereas banana TLP (Mus a 4) was not, in contrast with its homologous kiwi allergen Act d 2. Specific IgE to both banana allergens, as well as to peach Pru p 3, was found in over $70 \%$ of sera from banana-allergic children, and Mus a 4 and Pru $p 3$ provoked positive SPT responses in 6 of the 12 tested patients, whereas Mus a 5 in only one of them. Both peptidic epitopes and cross-reactive carbohydrate determinants were involved in the $\lg \mathrm{E}$-binding to Mus a 5 , whereas cross-reactivity between Mus a 4 and Act $d 2$ was only based on common lgE protein epitopes. Profilin Pho d 2 elicited a relevant proportion of positive responses on in vitro (41\%) and in vivo (58\%) tests. Therefore, Mus a 4 and LTP behave as major banana allergens in the study population, and profilin seems to be also a relevant allergen. Mus a 5 is an equivocal allergenic protein, showing high lgE-binding to its attached complex glycan, and low in vivo potency.
\end{abstract}

Allergy to banana (Musa acuminata) fruit is well established in the adult population worldwide, mainly in pollen-sensitized patients (1-3) and/or associated with latex allergy in the so called 'latex-fruit syndrome' $(4,5)$. Besides, banana-allergic subjects, sensitized to neither latex nor to pollen have been also described (2). In contrast, reported cases of allergic reactions to banana among children are scarce (6-8), in spite of this fruit being often introduced in the early infant diet, which may lead to an increase number of symptomatic cases in the infant population.

Only two banana allergens appeared in the List of Allergens of the IUIS Allergen Nomenclature Sub-Committee before the current study had been carried out. Mus a 1 is a $14 \mathrm{kDa}$ profilin showing an $\mathrm{lg} \mathrm{E}$-binding prevalence of $44 \%$ in 16 sera with suspected banana allergy and a high crossreactivity with its homologous allergens from other plant foods, latex and pollens (1). Mus a 2 corresponds to a $33 \mathrm{kDa}$ class I chitinase harboring a hevein-like $\mathrm{N}$-terminal domain, and represents a major banana allergen in patients suffering latex-fruit syndrome $(9,10)$. It displays very similar structural (i.e. amino acid sequence) and immunological properties to Pers a 1, its homologous class I chitinase and allergen from avocado fruit $(10,11)$. Currently, three additional banana allergens have increased the list: Mus a 3.0101, a non-specific lipid transfer protein (LTP), and Mus a 4.0101 and Mus a 5 , corresponding to the thaumatin-like protein (TLP) and b-1,3-glucanase, respectively, that are here reported. 
Besides Mus a 1 and Mus a 2, two additional banana fruit proteins ) b-1,3-glucanase and thaumatin-like ), have been claimed to be potential allergens, but no clinical data support this assumption at present. Banana endo-b-1,3-glucanase is a $33 \mathrm{kDa}$ pathogenesis-related (PR) protein belonging to the PR-2 plant protein family (12), whose putative role in the latex-fruit syndrome has been suggested, but not clearly demonstrated (13). The PR-2 family also comprises well-known allergens from rubber latex, Hev b 2 (14), and olive pollen, Ole e 9 (15). Both are N-glycosylated glucanases $(15,16)$, which have been proposed to be involved in latex- and/or pollen-plant food cross-reactivity (16-18), and behave commonly as minor allergens, although sensitization to Ole e 9 significantly increases in geographical areas where olive pollen exposure is high (19).

Banana $21 \mathrm{kDa}$ TLP is the second PR protein (PR-5 family) targeted as potential allergen (20). Homologous allergenic proteins have been described in plant foods and pollens (21). Thus, Act d 2 from kiwifruit (22), a food related to latex and banana allergy, has been recently identified as a major allergen in Spanish adults with kiwifruit allergy (23). Interestingly, Act d 2, as well as the apple thaumatin-like allergen Mal d 2, are glycoproteins with complex asparagine-linked glycans (22-24).

Banana b-1,3-glucanase and TLP have been isolated from fruit pulp in the current study, and their in vitro IgE-binding capacity and in vivo reactivity explored in a large number of pediatric patients sensitized to banana. Four additional relevant plant food allergens have also been tested for component-resolved diagnosis of banana allergy: kiwifruit Act d 2 to evaluate cross-reactivity with banana TLP, avocado Pers a 1 as representative class I chitinase involved in the latex-fruit syndrome, natural date palm pollen Pho $\mathrm{d} 2$ as a proper marker of profilin sensitization (25), and peach fruit Pru p 3 as LTP allergen model and most clinically relevant food allergen in the Mediterranean area (26).

\section{Methods}

\section{Patients and sera}

Fifty-one children with allergy to banana fruit were selected in the Servicio de Alergia, Hospital Infantil La Paz (Madrid, Spain), based on (i) a clinical history indicating allergic reactions (oral allergy syndrome, urticaria, vomiting, angioedema or anaphylaxis) after ingestion of banana fruit; (ii) a positive prick to prick test to the fresh fruit; and (iii) specific $\lg E$ levels to banana $>0.35 \mathrm{kU} / \mathrm{I}$, as determined by the CAP system FEIA (Phadia, Uppsala, Sweden). Demographic and clinical data of the selected patients are summarized in Table 1. None of these children but one (no. 27, Table 1) had allergic symptoms (urticaria) upon contact with latex products.

A subgroup of 12 patients (nos. $40-51$ in Table 1) were subjected to a skin prick test (SPT) with the purified allergens in a second study phase.

Written informed consents were obtained from parents of all patients, and the study was approved by the Ethical Committee of Hospital La Paz (Madrid).
Individual sera from all selected children were assayed for specific IgE determination and a serum pool ( $n=36$, nos. 1-36 in Table 1) in lgE immunodetection assays. In addition, six individual sera (nos. 2, 8, 24, 32, 38 and 43 in Table 1) were used in ELISA inhibition assays.

\section{Preparation of banana fruit extract}

A homemade banana extract was prepared following the method described by Anliker et al. (27). Briefly, peeled fruits were cut into pieces, ground in a mortar under liquid nitrogen, and then added to prechilled 4-hydroxy-4-methyl-2-pentanone () $20 \cdot \mathrm{C} ; 1: 3 \mathrm{w} / \mathrm{v})$, homogenized, and then chilled acetone $\left(020^{\circ} \mathrm{C} ; 1: 4 \mathrm{w} / \mathrm{v}\right)$ was added to the suspension, and homogenized again. The suspension was maintained overnight at ) $20 \cdot C$, then filtrated over a suction filter, and the power obtained washed with chilled acetone and acetonediethyl ether $(1: 1 \mathrm{v} / \mathrm{v} ;) 20 \bullet \mathrm{C})$. The filter residue was freeze dried, extracted with PBS buffer (100 mm potassium phosphate, $150 \mathrm{~mm} \mathrm{NaCl}, \mathrm{pH} 7.4 ; 1: 10 w / v, 1 \mathrm{~h}, 4 \cdot \mathrm{C}$ ), and centrifuged $(12,100 \mathrm{~g}, 30 \mathrm{~min}, 4 \cdot \mathrm{C})$. The supernatant was dialysed (cut-off point $3.5 \mathrm{kDa}$ ) against $\mathrm{H}_{2} \mathrm{O}$, freeze dried, and its protein concentration quantified according to the method of Bradford (28).

\section{Purification and characterization of allergens}

The banana extract was subjected to anion-exchange chromatography on a Waters Accell Plus QMA cartridge (Waters, Milford, MA, USA), equilibrated with $20 \mathrm{~mm}$ I-histidine $(\mathrm{pH}$ 5.0 ) buffer, and eluted with $0.5 \mathrm{~m} \mathrm{NaCl}$ in the same buffer. The non-retained material was dialysed (cut-off point $3.5 \mathrm{kDa}$ ) against $\mathrm{H}_{2} \mathrm{O}$, freeze dried, and then fractionated by cation-exchange chromatography on a Bio-Scale Mini Macro-Pep High S column (Bio-Rad, Hercules, CA, USA). The column was equilibrated with $20 \mathrm{~mm}$ formic acid $(\mathrm{pH}$ 4.0) buffer, eluted with a linear salt gradient to $0.5 \mathrm{~m} \mathrm{NaCl}$ in the same buffer $(0-0.5 \mathrm{~m}$ in $140 \mathrm{~min} ; 0.5 \mathrm{ml} / \mathrm{min})$, and eluted fractions were dialysed (cut-off point $3.5 \mathrm{kDa}$ ) against $\mathrm{H}_{2} \mathrm{O}$, freeze dried, and checked by SDS-PAGE fractionation and immunodetection with a serum pool from banana-allergic patients to detect banana b-1,3-glucanase and TLP. Pers a 1, the major allergen and class I chitinase from avocado fruit, was isolated by a method previously described (29). Act d 2, the thaumatin-like allergen from kiwifruit, was purified as described by Palacin et al. (23), and natural (n) and recombinant (r) Pru $\mathrm{p} 3$, the LTP allergen from peach fruit, as reported by Diaz-Perales et al. (30). Pho d 2, the natural profilin from date palm pollen, was supplied by ALK-Abello (Madrid, Spain). All four isolated allergens, as well as banana $b-1,3-g l u c a n a s e$ and TLP, were quantified using a commercial bicinchoninic acid test (Pierce, Cheshire, UK).

Identity and purity of allergens were ascertained by the following methods: (i) SDS-PAGE on Bio-Rad Miniprotean III System (Bio-Rad) gels (15\% polyacrylamide) under reducing conditions (31); and (ii) N-terminal amino acid sequencing using standard methods and an Applied Biosystem Procise 494 gas-phase sequencer (Foster City, CA, USA). 


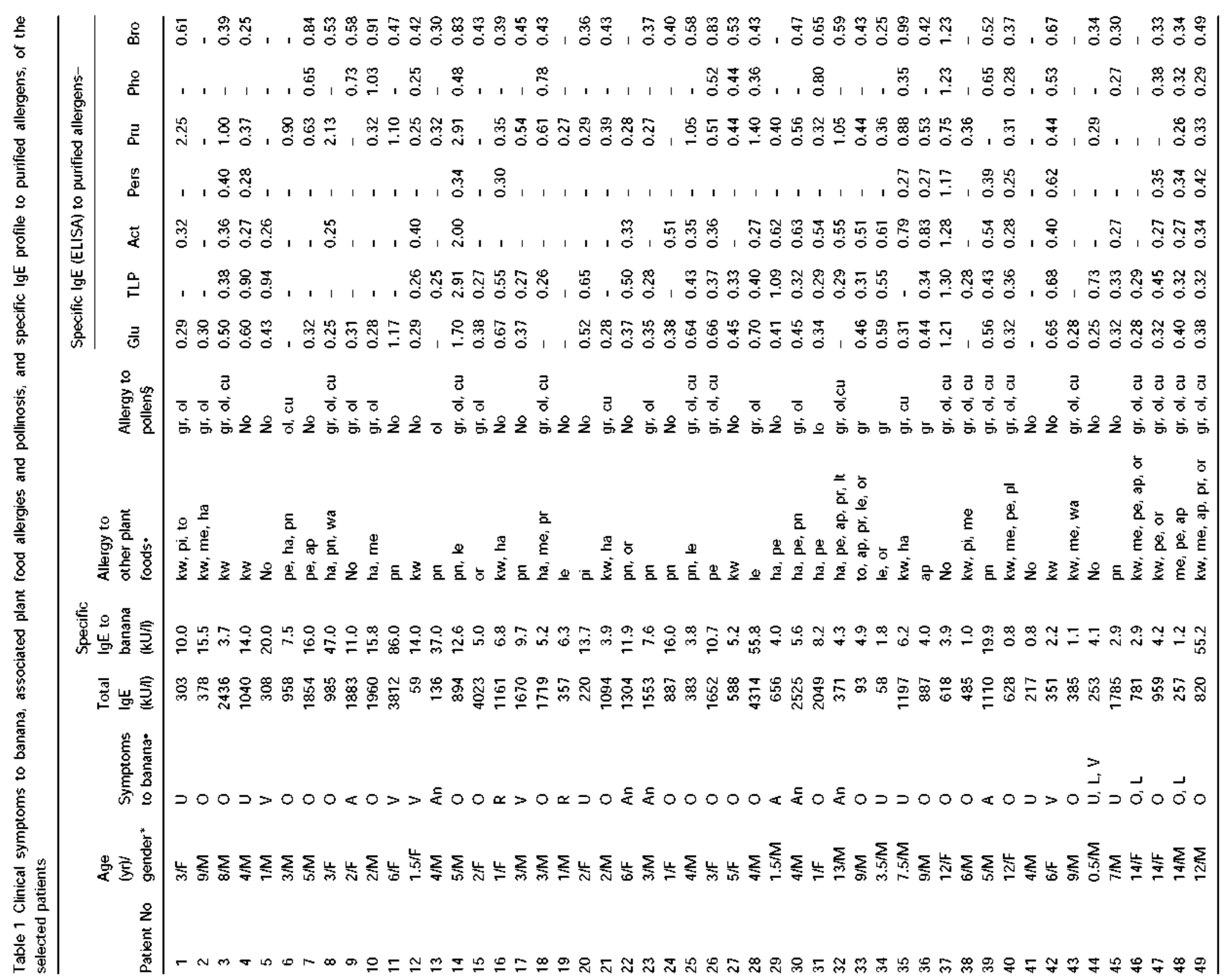




\begin{tabular}{|c|c|c|c|c|c|c|c|c|c|c|c|c|c|}
\hline \multirow[b]{2}{*}{ Patient No } & \multirow{2}{*}{$\begin{array}{l}\text { Age } \\
\text { (yr)/ } \\
\text { gender* }\end{array}$} & \multirow[b]{2}{*}{$\begin{array}{l}\text { Symptoms } \\
\text { to banana. }\end{array}$} & \multirow{2}{*}{$\begin{array}{l}\text { Total } \\
\text { lgE } \\
(\mathrm{kU} / \mathrm{l})\end{array}$} & \multirow{2}{*}{$\begin{array}{l}\text { Specific } \\
\text { lgE to } \\
\text { banana } \\
\text { (kU/l) }\end{array}$} & \multirow{2}{*}{$\begin{array}{l}\text { Allergy to } \\
\text { other plant } \\
\text { foods. }\end{array}$} & \multirow[b]{2}{*}{$\begin{array}{l}\text { Allergy to } \\
\text { pollen§ }\end{array}$} & \multicolumn{7}{|c|}{ Specific lgE (ELISA) to purified allergens- } \\
\hline & & & & & & & Glu & TLP & Act & Pers & Pru & Pho & Bro \\
\hline 50 & $1.25 / \mathrm{M}$ & U & 112 & 2.4 & No & No & 0.46 & 0.47 & 0.41 & 0.32 & 0.50 & 0.45 & 0.39 \\
\hline 51 & $12 / \mathrm{M}$ & 0 & 1746 & 16.0 & pe & $\mathrm{gr}, \mathrm{ol}, \mathrm{cu}$ & - & 0.25 & 0.28 & 0.27 & 0.73 & 0.31 & 0.32 \\
\hline
\end{tabular}

* F, female; $M$, male.

-U, urticaria; $\mathrm{O}$, oral allergy syndrome; $V$, vomiting; $A$, anaphylaxis; An, angiodema; $R$, rejection; $L$, lip edema.

- Kw, kwi; pi, pineapple; to, tomato; me, melon; ha, hazelnut; pe, peach; pn, peanut; ap, apple; wa, walnut; le, lentil; or, orange: pr, pear; lt, lettuce; pl, plum.

$\S g r$ grass; ol, olive: cu, Cupressus; lo, Lolium.

-Values (OD units) >0.24 OD units were considered positive (see Methods). Gluc, banana b-1,3-glucanase; TLP, banana thaumatin-like protein; Act, kiwifruit thaumatin-like protein Act d 2; Pers, avocado class I chitinase Pers a 1; Pru, peach lipid transfer protein Pru $p$ 3; Pho. palm pollen profilin Pho d 2; Bro, pineapple bromelain (marker of plant complex glycans).

\section{Immunodetection assays}

Banana extract (20 $\mathrm{lg}$ of protein) and isolated allergens (3 Ig) were fractionated by SDS-PAGE, electrotransferred onto polyvinylidene difluoride membranes and IgE immunodetected essentially as previously described (23). A serum pool ( $n=36$; nos. 1-36 in Table 1) from banana-allergic patients (1:20 dilution) and goat anti-human $\lg E$-peroxidase conjugate (Biosource, Camarillo, CA, USA; 1:3000 dilution) were used, and $\lg \mathrm{E}$-binding components detected by means of chemiluminiscence (Amersham Biosciences, Little Chalfont, UK). A pool of sera ( $n=10$ ) from patients with dust mite, but not plant food or pollen allergy, was assayed as negative control.

Alternatively, blocked membranes were immunodetected with rabbit polyclonal antibodies to plant complex asparagine-linked glycans (32) (1:10,000 dilution), and then treated with goat anti-rabbit IgG-peroxidase conjugate (Dako, Carpinteria, CA, USA; 1:10,000 dilution) and revealed by means of chemiluminiscence (Amersham Biosciences).

\section{Specific $\lg E$ determination and ELISA-inhibition assays}

Individual sera (1:15 dilution) from banana-allergic patients were tested by a direct ELISA assay previously reported (23) to determine specific $\mathrm{lgE}$ to banana extract $(20 \mathrm{lg} / \mathrm{ml}$ in solid phase) and purified natural banana b-1,3-glucanase and TLP, nAct d 2, nPers a 1, nPho d 2, rPru p 3 and commercial bromelain (Sigma, St Louis, MO, USA) ( $3 \mathrm{Ig} / \mathrm{ml}$ each in solid phase). Blocking solution (Sigma) without solid phase In = 69; mean (OD units) \pm s.d. $=0.09 \pm 0.05$ ], and a serum pool ( $n=10)$ from patients allergic to dust mite, but not to plant food or pollen $[\mathbf{n}=10$; means $(\mathrm{OD}) \pm$ s.d. to banana extract $=0.08 \pm 0.02$, to banana $\mathrm{b}-1,3$-glucanase $=0.11 \pm$ 0.04, to banana TLP $=0.05 \pm 0.06$, to Act d $2=0.09 \pm 0.04$, to Pers a $1=0.13 \pm 0.03$, to Pho d $2=0.09 \pm 0.04$ and to Pru p $3=0.06 \pm 0.06$ ] were tested as negative controls. Specific lgE levels $>0.24$ OD units were considered to be positive (highest value of mean $+3 \cdot$ s.d. of negative controls). All tests were carried out in triplicate.

ELISA-inhibition assays were performed by the same method, except that the sera were previously incubated $(3 \mathrm{~h}, 25 \cdot \mathrm{C})$ with the appropriate inhibitor. Different purified allergens were tested as solid phase $(3 \mathrm{Ig} / \mathrm{ml})$ and/or inhibitors ( 3 and $6 \mathrm{Ig} / \mathrm{ml}$ ). All assays were carried out in triplicate.

\section{Skin prick tests}

SPTs with banana extract (2 $\mathrm{mg}$ of protein $/ \mathrm{ml}$ ) and purified banana b-1,3-glucanase, TLP, nAct $d 2$, nPers a 1 and nPho d $2(50 \mathrm{lg} / \mathrm{ml})$, and $\mathrm{nPru} p 3(20 \mathrm{lg} / \mathrm{ml})$ in a $1: 1(\mathrm{v} / \mathrm{v})$ PBS buffer/glycerol solution, were performed according to standard procedures (33). Histamine dihydrachloride $(10 \mathrm{mg} / \mathrm{ml})$ and PBS buffer/glycerol solution served as positive and negative controls, respectively. A mean wheal diameter of $3 \mathrm{~mm}$ or larger (15 min after puncture) than that produced by the negative control was considered a positive response. Three healthy subjects were tested with all samples as a control group. Duplicate of each sample were assayed in patients and control subjects.

\section{Statistics}

Correlation between specific $\lg E$ levels to the different allergens tested was determined by one-way intraclass correlation coefficient (ICC), performed at a significant level of $p<0.05$. Tests were carried out using the spss statistical software version 12 for Windows (SPSS Inc., Chicago, IL, USA).

\section{Results}

\section{Clinical characteristics of selected patients}

All 51 selected patients were children (mean age: 5.3 yr; range 0.5-14 yr; 18 girls $/ 33$ boys) showing adverse reactions after 


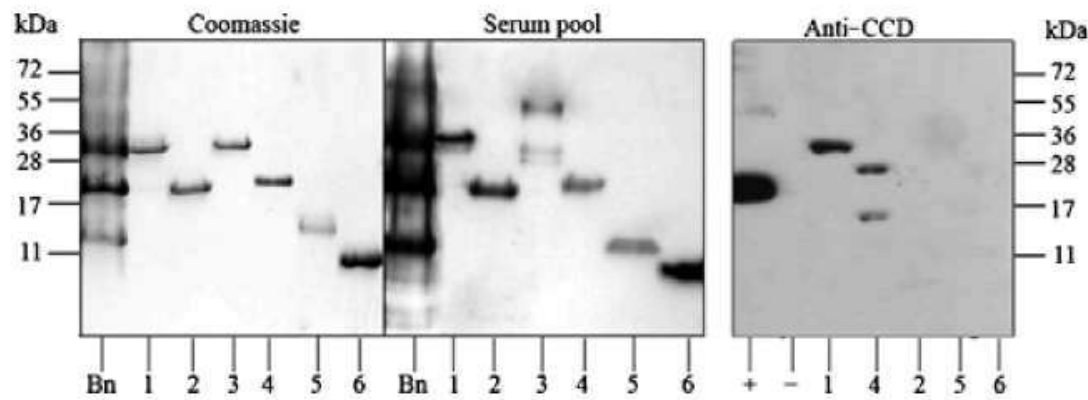

Figure 1 Protein staining (Coomassie) and immunodetection with $\mathrm{lg} \mathrm{E}$ of a serum pool from banana-allergic patients (Serum pool) or rabbit polyclonal antibodies to plant complex glycans [Anti-crossreactive carbohydrate determinant $(C C D)]$ of the following samples separated by SDS-PAGE: banana fruit extract $(B n)$, banana b-1,3- glucanase (1), banana thaumatin-like protein (2), avocado class I chitinase Pers a 1 (3), kiwifruit thaumatin-like protein Act d 2 (4), palm pollen profilin Pho $\mathrm{d} 2(5)$ and peach lipid transfer protein Pru p 3 (6). Bromelain (+) and bovine serum albumin ()) were used in panel Anti-CCD as positive and negative control, respectively. banana ingestion and specific IgE to this fruit (Table 1). Oral allergy syndrome was found in $53 \%$ of subjects, and systemic reactions (mainly urticaria and vomiting), including anaphylaxis $(n=3)$ in $47 \%$ of them.

Most patients $(86 \%)$ had also allergic symptoms to other plant fruits and nuts (Table 1), kiwi (35\%), peanut (29\%), hazelnut $(27 \%)$, peach $(27 \%)$ and melon $(20 \%)$, being the most frequent. Furthermore, up to $65 \%$ of the selected children were also allergic to pollen, but almost exclusively to grass $(91 \%)$, olive $(82 \%)$ and/or Cupressus $(61 \%)$ pollen (Table 1).

\section{Isolation and characterization of putative banana allergens}

Two abundant proteins in the banana pulp extract (Fig. 1 Coomassie, lane $\mathrm{Bn}$ ), namely b-1,3-glucanase (Gluc) and $T L P$, previously proposed as putative allergens $(12,20)$, were isolated from this extract by a two-step chromatographic procedure (not shown). Purity of each obtained allergen was ascertained by the presence of a single protein band of the expected apparent molecular weight after SDS-PAGE separation (Fig. 1 Coomassie, lanes 1 and 2), and a single determined $\mathrm{N}$-terminal amino acid sequence (up to 27 residues for each protein, Fig. 2).

Gluc, the purified $30 \mathrm{kDa}$ protein, showed a N-terminal amino acid sequence (27 residues) identical to that of Unigen accession gl 83754908 (mature protein; Fig. 2a), which corresponds to the banana endo- b-1,3-glucanase whose crystal structure was reported by Receveur-Brechot et al. (12). Gluc was glycosylated (Fig. 1 Anti-CCD), as indicated by its recognition by anti-complex asparagine-linked glycans antibodies.

Regarding TLP, the isolated $20 \mathrm{kDa}$ putative allergen, its first $28 \mathrm{~N}$-terminal residues fully matched the corresponding ones of the Unigen accession gl 88191901 amino acid sequence (mature protein; Fig. 2b), which encodes the banana TLP whose 3D-structure was resolved by Leone et al. (20). Interestingly, TLP was not glycosylated by attachment of $\mathrm{N}$-linked complex glycans (Fig. 1 Anti-CCD), in contrast with its kiwi homologous allergen Act d 2, which presented the two glycosylated forms previously described (23).

Specific IgE to banana Gluc and TLP and to other representative plant food allergens

Both purified banana Gluc and TLP, as well as avocado Pers a 1, kiwifruit Act d 2, palm pollen Pho $d 2$ and peach Pru $p$ 3 , were recognized by a serum pool $(n=36)$ from banana allergic patients in $\mathrm{IgE}$ immunodetection assays (Fig. 1 Serum pool). Aggregates with strong IgE-binding capacity were detected in Pers a 1 , in line with results previously reported (11). A pool of sera tested as negative control (see Methods) recognized neither purified allergen nor band in the banana extract (not shown).

The potential relevance of Glu and TLP as banana allergens was suggested by the high number of sera showing specific $\lg E$ to each purified protein. Thus, $84 \%$ and $72 \%$ of the 51 sera from banana-allergic patients showed specific $\operatorname{IgE}$ to Gluc and TLP, respectively (Table 1 and Fig. 3). On the other hand, a high prevalence (over $75 \%$ of sera with specific $\operatorname{lgE}$ to) was also found for peach Pru p 3 and pineapple bromelain (marker of cross-reactive carbohydrate determinants, CCDs), and (over 50\%) for kiwifruit Act d 2, whereas avocado Pers a 1 and profilin Pho d 2 reached values under $50 \%$ (Table 1 and Fig. 3).

Both B-cell peptidic epitopes and cross-reactive carbohydrate determinants are involved in the $\mathrm{IgE}$-binding to banana Gluc

The glycosylation of Gluc led to evaluate the role of CCDs in its $\lg \mathrm{E}$-binding capacity. Therefore, individual sera displaying two different specific IgE profiles to Gluc and bromelain were analyzed by ELISA-inhibition assays (Fig. 4a,b). Sera from patients monosensitized to Gluc (only two; see Table 1) indicated the presence of $\lg E$ epitopes linked to the protein structure and non-sensitive to CCDs, whereas those from subjects polisensitized to Gluc, Act d 2 and bromelain 
(a)

Allergen

Banana glucanase Latex Hev b 2 Olive Ole e 9

Banana glucanase Latex Hev b 2

Olive Ole e 9

Banana glucanase La tex Hev b 2 Olive Ole e 9
Amino acid sequence

--IEV CY GML GNILP PP SEVUS LY KSNNIARMRL YDPNQAAL QALRNSNIQVLL DV PRS - -QVGVCYGMQ GNNLP PVSEVIA LY KRSNITRMRI YDPNRAVL BALR GSNIELIL GV PNS QSFLGVNYGQL SDNLP SLQATUNLL KST IIQKVRL PGA EPAVI KA EANIGVE IVI GE DNG

DUQSLA SNPSA.AGDWI RRNVVAYWP SUSERY IA VGNELI PGSD-- - LAQYIL PAMRNIY DLQSLT-NPSNAR SWV QKAVR GEWS SVL FRY IA VGNEISPVNR GT AW LAQFVL PAMRNIH DIPTLA SNPNVAS QDVKSNUMSF YP ASNI IAITVGNEVLTSGD CK-IISQLLPAMQNVQ

NAL SSA GLQNQ IKVST AVDT GVL GT SYPPSAGA FS SAA QAYLS PI VQ FLASNGAPILVIV DAI RSA GLQDQ IRVST AIDLTLVGNSYPPSAGA FR DDVRSYLD PI IG FLSSIRSPILANI NALNAA SLGGKVKVST VHAMAVL SQ SY PPSSGV BN PGL GDTMKAL LQ EQSANDAP IMISP

Banana glucanase La tex Hev b 2 Olive Ole e 9

Y PY FSY TGNPGQI SLP YALFTAS GVVVQDGR-FSY CNL FDAIVDAVE AALERVGGANVAV Y PY FTYAYNPR DI SLP YALFT SP SVVVWDGQ-R GYKRL FDATL DA LY SALERASGGSIEV Y PY FAY KNQPT PD TLA ICLFQPNAG QVDSGNGH KY TM FDAQVDA VH SALNAMGE KD IEI

Banana glucanase Latex Hev b 2 Olive Ole e 9

VUS ESGWPSAGG--GAEASTSNART YNQNLIRHVGG--GIPRR PGKE IEAYIFPMANMNQ VUS ESGWPSAG---AFAAT FDNG RT YLSNLICHVKG--GTPKR PNRA IETYLFAM FD BNK VVA ETGWPHGG DSNEV GPSLDNA KA YVGNL INHIKSKV GT PIM PG KS IDTYLFSL YD EDK

Banana glucanase Latex Hev b 2

KAGG-IEQNPGLIYPNKQPVYQISE KQPE-VBKHAGLF FPNKWQKYNLNE SA KIGASS BKY FGLTKPD GSITYDVGLIK (b)

\section{Allergen}

Cupressus Cap s

Apple Mal d 2
Banana TLP

\section{Amino acid sequence}

ATFEIVNRCSY TVWAAAVPGGGR -------QLNQ GQSWTINVNA GT TGGRIWGR TGCSF 2 ATFNIINNCPETVWAAAVPGGGK-----2L DR GQNW I INP GA GT KGARVWPR TGCNF 3 VKF DIKNQCRY TVWAA GLPGGGK------RL DQ GQTWTVIL AA GT ASAR FWGR TGCTF AKI TFT NNCPN TVWPG TLTGDCK PQ LSLTGFILAS KAS RSVAA PS -PWSGRFWGR TRCST

Banana TLP DGS GRGRCQTGDCG-GVLSCTAYGN PP-NTLAE FALNQ FNNLD FF DI SLVDGFNV PMDFS

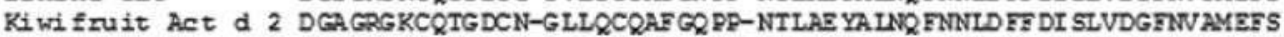
Cupressus Cup $s$ I DASGKGSCRSGDCG-GQLSCTVS GAVP-ATLAEYTQ--SDCDYYDVSLVDGFNI PLAIN Apple Mal d 2 DAAGKITCETADCSGQVACNGA GA VPPATLVE IT IAANGGQD YY DV SLVDGENL PMSVA

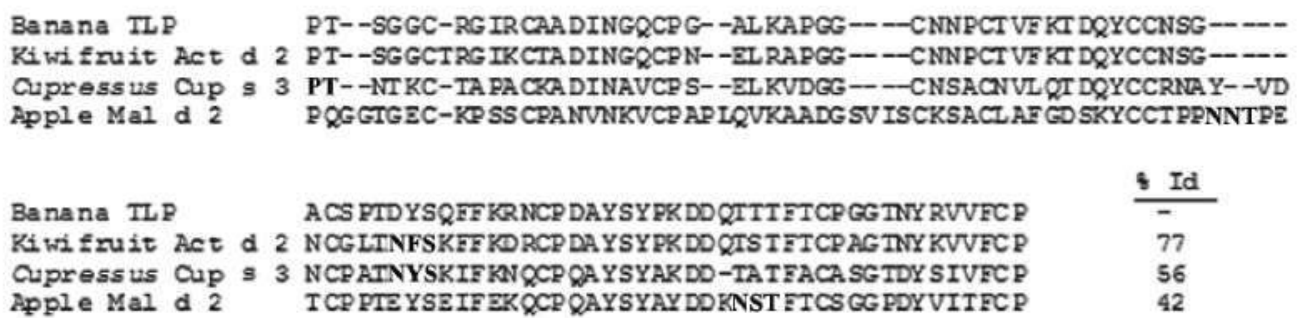

Figure 2 Alignment of full amino acid sequences of (a): banana b-1,3-glucanase (accession no. gi 83754908), latex Hev b 2 (accession no. P52407) and olive pollen Ole e 9 (without its C-terminal domain; accession no. Q94G86). (b): banana thaumatin-like protein (accession no. gi 88191901), kiwifruit Act d 2 (accession no. P81370), Cupressus sempervirens pollen Cup s 3 (accession no.

(25 patients; see Table 1) showed major IgE-binding to plant complex glycans.

In contrast, similar ELISA-inhibition assays (Fig. 4c) supported that cross-reactivity between non-glycosylated banana
Q69C52) and apple Mal d 2 (accession no. Q3BCT4). The N-terminal gray-highlighted sequences were confirmed by protein sequencing of the isolated allergens. Sequence identities to banana b-1,3glucanase or thaumatin-like protein (\% Id) are indicated on the right side. Potential $\mathrm{N}$-glycosylation sites are marked (bold letters) in panel $b$.

TLP and its glycosylated kiwifruit homologous Act d 2 was only based on $\operatorname{lgE}$ peptidic epitopes. A strong correlation $(I C C=0.760 ; p<0.0001)$ of specific $\lg E$ levels to banana TLP and Act $d 2$ was found in the population $(n=51)$ study. 


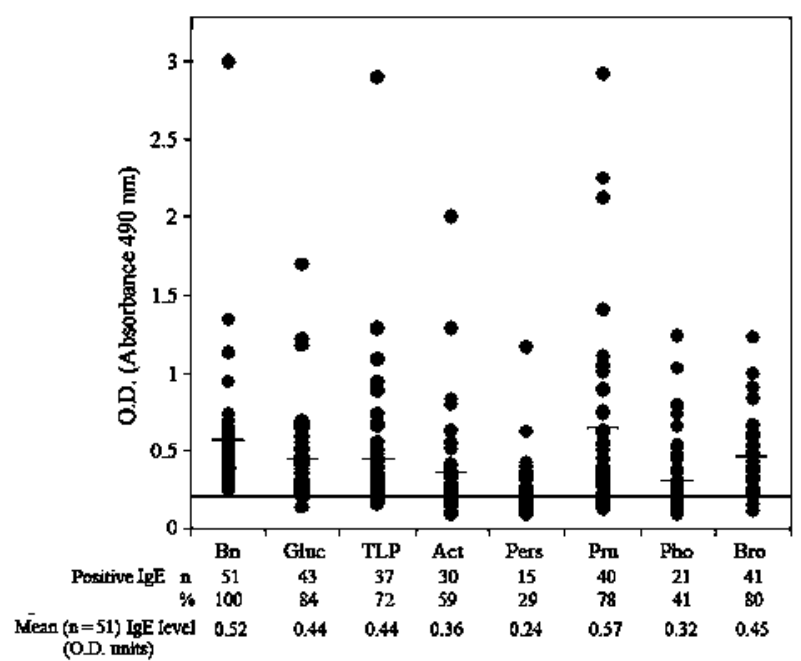

Figure 3 Sensitization to banana potential allergens and other plant food allergens of pediatric banana-allergic patients $(n=51)$. Values (mean; $n=3$ ) are specific $\lg E$ levels (OD units) to banana fruit extract (Bn) and purified allergen banana b-1,3-glucanase (Gluc) and thaumatin-like protein (TLP), kiwifruit thaumatin-like protein Act d 2 (Act), avocado class I chitinase Pers a 1 (Pers), peach lipid transfer protein Pru p 3 (Pru), palm pollen profilin Pho d 2 (Pho) and pineapple bromelain (Bro; marker of plant complex glycans). Values $>0.24$ OD units (long horizontal line) were considered positive (see 'Methods'). Mean values for each solid phase were indicated as short horizontal lines.

In vivo reactivity of banana Gluc and TLP and other representative plant food allergens

SPTs with the six purified plant food allergens tested in this study were carried out in 12 banana-allergic patients showing positive in vivo response to the banana extract. The results obtained were compared with those of in vitro specific $\mathrm{IgE}$ determination (Table 1), and shown in Table 2. Positive SPT responses in around $50 \%$ of patients were found for banana TLP, peach Pru p 3 and palm pollen Pho d 2, roughly in line with the corresponding in vitro results. In contrast, under $20 \%$ of subjects responded to the glycosylated allergens banana Gluc and kiwifruit Act d 2 whereas specific $\operatorname{lgE}$ to each of them was found in over $65 \%$ of the same subjects. A low rate ( $8 \%$ of patients) of positive SPT responses was also induced by avocado Pers a 1 .

\section{Discussion}

Banana should be considered a putative important allergenic food source, based on its extensive consumption by the adult population, early introduction in infant diets, and involvement in allergic disorders, such as the latex-fruit syndrome. Particularly, an increasing number of non-reported symptomatic cases of infants with banana hypersensitivity have seemed to emerge in Spain and other European countries (34). However, limited care has been devoted to banana allergy and its allergens in the last decade. The aim of this work was to assess the relevance of two banana proteins, as well as of several representative plant food allergens, as allergens linked to banana hypersensitivity in a selected large group of children with allergy to banana.

The two isolated banana proteins, unambiguously identified as b-1,3-glucanase (Gluc) and TLP, respectively, seemed to be among the most abundant (Fig. 1 Coomassie) and strongest IgE-binding (Fig. 1 Serum pool) components of the banana extract. Taking into account that both are natural allergens, the potential presence of more than one isoform in each protein preparation can not be discarded.

Gluc, recently designated as Mus a 5 by the IUIS Allergen Nomenclature Sub-Committee, harbored cross-reactive carbohydrate determinants (CCDs) (35). The CCDs played an important role in the lgE-binding capacity of Mus a 5 (Fig. 4), and partly explained the great difference between its in vitro (specific IgE detected in $84 \%$ of sera from banana-allergic infants) and in vivo ( $8 \%$ of positive SPT responses) reactivity. A similar behavior has been described for other glycosylated allergens from plant foods, such as orange germin-like glycoprotein Cit s 1 (36). However, the identification of monosensitized patients to (Table 1, nos. 2 and 43), and IgE peptidic epitopes (Fig. 4a) of Mus a 5 , supported its true allergenic potency. Furthermore, cross-reactivity with other allergenic plant b-1,3-glucanases also $\mathrm{N}$-glycosylated, such as rubber latex $\mathrm{Hev}$ b 2 and olive pollen Ole e 9 (14-16), a potentially relevant and unknown issue in plant foods and pollens co-sensitizations, has to consider both CCDs and protein epitopes. In this context, the comparison of natural and deglycosylated forms of the allergenic b-1,3-glucanases mentioned above in different in vitro and SPT assays will clarify the role of complex Asn-linked glycans in both IgE-binding and cross-reactivity.

The second isolated banana fruit protein, TLP, named Mus a 4.0101 by the IUIS Allergen Nomenclature SubCommittee, was not glycosylated, contrary to other allergenic TLPs, such as those from kiwi and apple $(23,24)$. Mus a 4 is a major banana allergen in the pediatric population herein investigated, as indicated by both its in vitro ( $72 \%$ of sera with specific $\operatorname{lgE}$ to) and in vivo (50\% of positive SPT responses) reactivity. The relevance of other TLP food allergens widely varies, from major allergens in kiwifruit (23) to low reacting in apple (37). Moreover, very different prevalences (\% of sera with specific $\mathrm{IgE}$ ) have been reported for the same TLP allergen, such as Act d 2 (23, 38). ELISA-inhibition assays have allowed to detect common peptidic IgE epitopes in Mus a 4 and Act d 2 (Fig. 4 c), thus supporting cross-reactivity between TLP allergens besides the presence of CCDs. Furthermore, the immunological closeness between the banana and kiwi allergens could partly explain why kiwifruit is the main plant food associated with banana in this pediatric study group (Table 1). Palacin et al. (39) have recently identified peach TLPs as potential major allergen of this fruit in the Spanish adult population, thus further supporting the role of TLPS as putative panallergens involved in plant food allergy and pollen/food co-sensitization. 


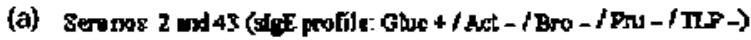

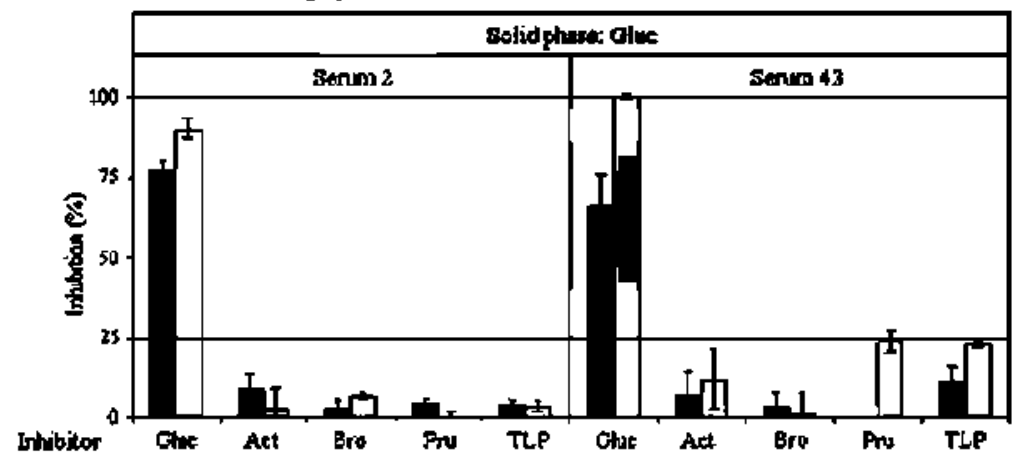

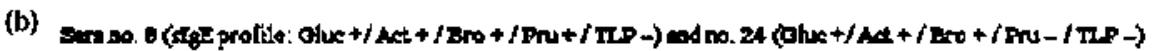
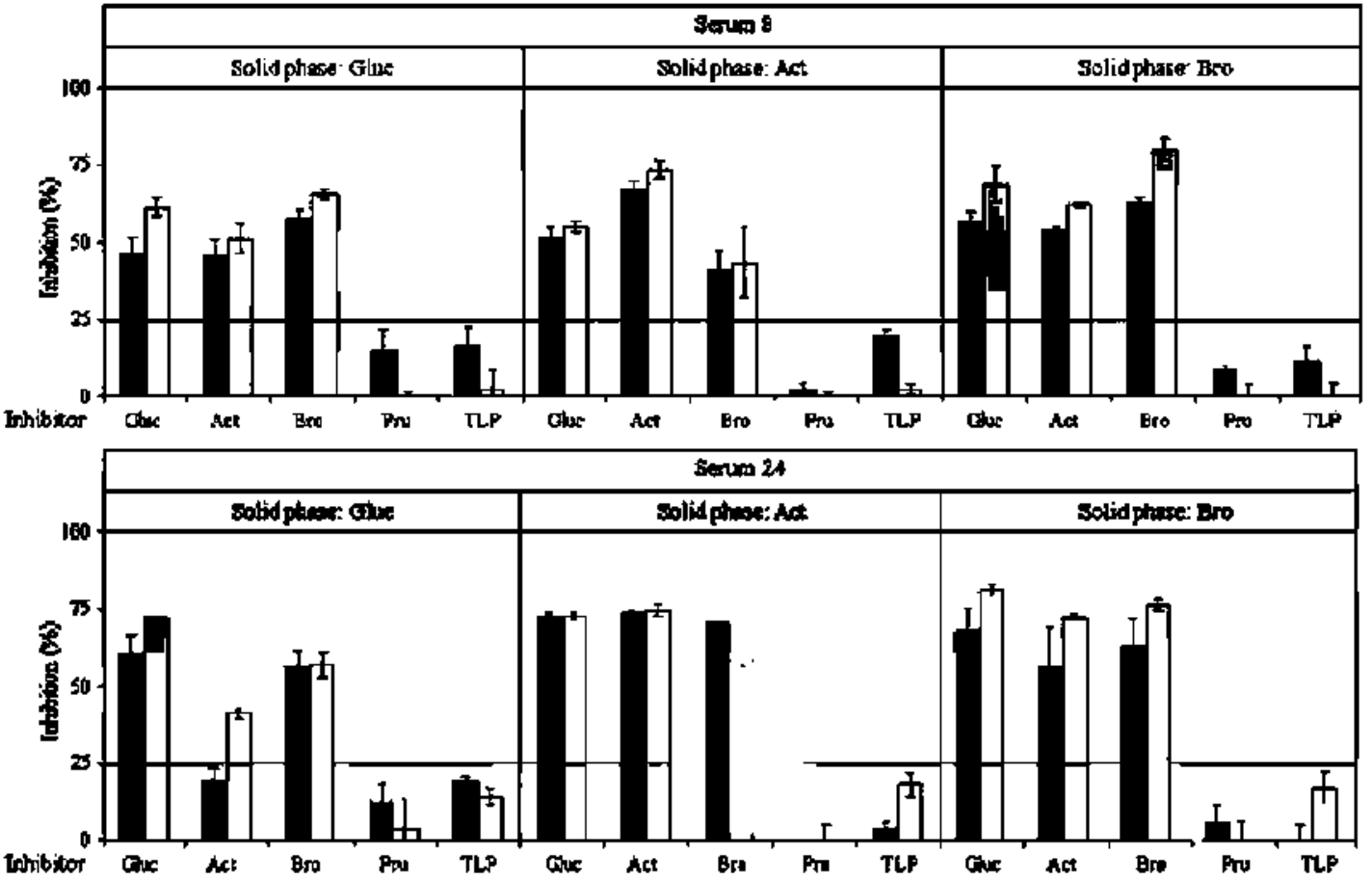

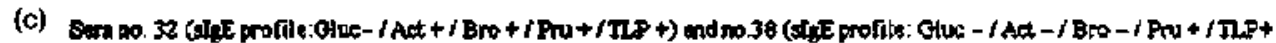

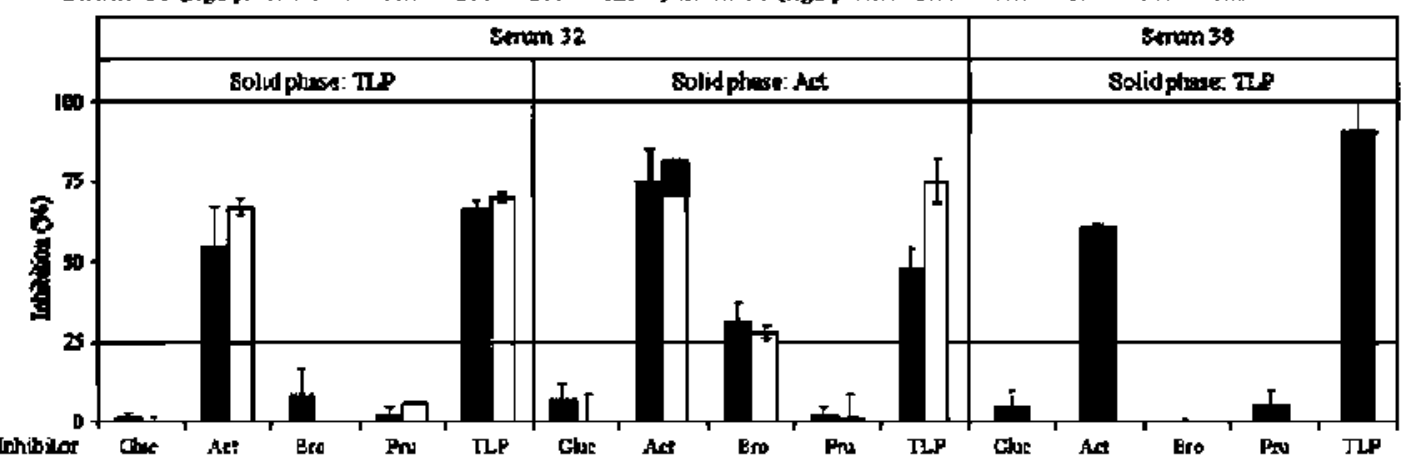

Figure 4 ELISA-inhibition assays using individual sera from banana-allergic patients with different specific $\lg \mathrm{E}$ (slgE) profiles to purified banana allergens. Appropriate purified allergens were used as solid phase ( $3 \mathrm{lg} / \mathrm{ml})$ andior inhibitors $(6 \mathrm{lg} / \mathrm{ml}$ : gray bars, and
$3 \mathrm{Ig} / \mathrm{ml}$ : black bars). Serum numbers (no.) correspond to those of Table 1. Abbreviations of purified allergens are as in Table 1 and Fig. 4. Means $(n=3)$ and s.d. (narrow bars) are represented. 
Table 2 Skin prick test (SPT) responses to banana extract (Bn) and to purified allergens banana b-1,3-glucanase (Gluc) and thaumatinlike protein (TLP), kiwifruit thaumatin-like protein Act d 2 (Act), avocado class 1 chitinase Pers a 1 (Pers), peach lipid transfer protein Pru p 3 (Pru) and palm pollen profilin Pho d 2 (Pho) in banana-allergic patients (nos 40-51 in Table 1)

\begin{tabular}{|c|c|c|c|c|c|c|c|c|}
\hline & $B n$ & Gluc & TLP & $\mathrm{Act}$ & Pers & Pru & Pho & Bro* \\
\hline \multicolumn{9}{|c|}{ Positive SPT responses• } \\
\hline$n=12$ & 12 & 1 & 6 & 2 & 1 & 6 & 7 & nd \\
\hline$\%$ & 100 & 8 & 50 & 17 & 8 & 50 & 58 & nd \\
\hline \multicolumn{9}{|c|}{ Positive slgE. } \\
\hline$n=12$ & 12 & 10 & 10 & 8 & 7 & 7 & 8 & 9 \\
\hline$\%$ & 100 & 83 & 83 & 67 & 58 & 58 & 67 & 75 \\
\hline
\end{tabular}

*Pineapple bromelain (marker of plant complex glycans), nd, not determined.

- Mean weal diameter $\cdot 3 \mathrm{~mm}$ (see Methods).

- See Table 1, patients 40-51.

On the other hand, molecular markers of three important allergen families linked to fruit allergy have rendered different results. Peach Pru p 3, tested as representative member of LTPS, has behaved as a major allergen in the group of selected banana-allergic patients. Up to $78 \%$ and $50 \%$ of positive specific $\mathrm{lgE}$ determinations and SPTs, respectively, were obtained. Food allergy related to LTPs, particularly peach Pru p 3, is the most frequent plant food allergy in Mediterranean adults, peach being the food that probably provokes the primary sensitization to these allergens in most patients $(26,37,40,41)$. Interestingly, the prevalence of sensitization to Pru $\mathrm{p} 3$ in pediatric subjects has been recently found twice as high as in adults among pollen-allergic subjects from Southern and Central Spain, although no relationship between sensitization to this allergen and any specific pollinosis was found (19). A Pru p 3 homologous allergen ( $40 \% \mathrm{~N}$-terminal amino acid sequence identity; 22 residues), named Mus a 3 by the IUIS Allergen Nomenclature Sub-Commitee has been detected in banana fruit, but the very low levels of this LTP in the extract from banana pulp has prevented its isolation in sufficient amount to carry out specific $\lg E$ determinations in individual sera using the purified allergen. The putative prevalence of Mus a 3 has been estimated by lgE immunodetection of a banana fruit extract with individual sera from bananaallergic patients ( $n=36$ ), showing recognition levels of the putative Mus a 3 - SDS-PAGE band by around $20 \%$ of the sera tested. However, the low amount of Mus a 3 in the banana fruit extract strongly suggests revising this estimated prevalence ( $R$. Sanchez-Monge, personal communication). On the other hand, no banana reactivity has been found in adult LTP-allergic patients from Italy, and this fruit has been consequently proposed as a safe food for LTP-allergic subjects $(42,43)$. Thus, cross-reactivity between Pru p 3 and Mus a 3, as well as the putative role of the latter as primary sensitizer in banana allergy, remain to be clarified.

Profilin sensitization, using date palm pollen Pho d 2 as proper marker (25), seems also relevant in the group of banana-allergic children. Positive responses were found in $40-50 \%$ of the subjects by both ELISA assays and SPTs. This prevalence is similar to that observed (44\%) testing specific $\lg E$ to recombinant Mus a $\mathbf{1}$ (banana profilin) in sera from German adults with birch pollen allergy and allergic reactions to banana (1). In contrast, class I chitinases with N-terminal hevein-like domain, represented by avocado Pers a 1 (11) have shown low specific IgE prevalence (29\%) and in vivo potency (positive response in 1 out of 12 patients). Mus a 2, the banana class I chitinase, has been identified as a major allergen in subjects with latex-fruit syndrome (10). However, this syndrome is almost absent (only one child was allergic to latex) in the pediatric population studied, indicating that both profiles and, most probably, cross-reactive routes of sensitization, are different from those in adult groups previously studied $(9,10)$. Nevertheless, future research on sensitization to latex Hev b 6 in this population will help to determine its possible relationship with latex allergy.

In summary, most infants with allergy to banana were sensitized to many allergen families, and, particularly, a high proportion to CCDs. Mus a 4 (TLP) and peach LTP Pru p 3 behave as major allergens, and profilin as a relevant one, in the group of patients herein investigated. Mus a 5 (b-1,3-glucanase) seems to be an equivocal allergenic protein displaying very high specific IgE prevalence, predominantly due to reactivity to CCDs, but shows low in vivo reactivity.

\section{Acknowledgments}

We thank Ms Dolores Lamoneda for her expert secretarial support. Financial support was provided by Ministerio de Ciencia e Innovacion-DGI (grant B|O2009-07050) and Instituto de Salud Carlos III, Redes de Investigacion Cooperativa (RIRAFF; ref RD07/0064/03).

\section{References}

1. Reindl J, Rihs HP, Scheurer $S$, Wangorsch A, Haustein D, Vieths $\$$. IgE reactivity to profilin in pollen-sensitized subjects with adverse reactions to banana and pineapple. Int Arch Allergy Immunol 2002: 128: 105-14.

2. Grob $M$, Reind J, Vieths $S$, Wuthrich $B$, Ballmer-Weber BK. Heterogeneity of banana allergy: characterization of allergens in banana-allergic patients. Ann Allergy Asthma Immunol 2002: 89: 513-6.

3. Miralles JC, Caravaca F, Guillen F, Lom-

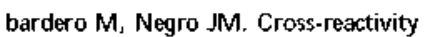
between Platanus pollen and vegetables. Allergy 2002: $57:$ 146-9.

4. Blanco C. Latex-fruit syndrome. Curr Allergy Asthma Rep 2003: 3: 47-53.
5. Brehler R, Theissen U, Mohr C, Luger T. 'Latex-fruit syndrome'; frequency of crossreacting IgE antibodies. Allergy 1997: 52: 404-10.

6. Moreno-Ancillo A, Dominguez-Noche $C$, Gil-Adrados AC, Cosmes PM. Allergy to banana in a 5-month-old infant. Pediatr Allergy Immunol 2004: 15: 284-5. 
7. Hauswirth DW, Burks AW. Banana anaphylaxis with a negative commercial skin test. J Allergy Clin Immunol 2005: 115: 6323.

8. Ito A, Ito $\mathrm{K}$, Morishita M. Sakamoto T. A banana-allergic infant with $\lg E$ reactivity to avocado, but not to latex. Pediatr Int 2006: 48: 321-3.

9. Mikkola JH, Alenius $\mathrm{H}$, Kalkkinen N, Turjanmaa K, Palosuo T, Reunala T. Heveinlike protein domains as a possible cause for allergen cross-reactivity between latex and banana. J Allergy Clin Immunol 1998: 102: 1005-12.

10. Sanchez-Monge $R$, Blanco $C$, Diaz-Perales $A_{1}$ et al. Isolation and characterization of major banana allergens: identification as fruit class I chitinases. Clin Exp Allergy 1999: 29: 673-80.

11. Diaz-Perales A, Collada C, Blanco C, et al. Class I chitinases with hevein-like domain. but not class II enzymes, are relevant chestnut and avocado allergens. J Allergy Clin Immunol 1998: 102: 127-33.

12. Receveur-Brechot $V$, Czjzek $M$, Barre $A$, et al. Crystal structure at 1.45-A resolution of the major allergen endo-b-1,3-glucanase of banana as a molecular basis for the latex. fruit syndrome. Proteins 2006: 63: 235-42.

13. Barre A, Culerrier $R$, Granier $C$, et al. Mapping of IgE-binding epitopes on the major latex allergen Hev b 2 and the cross-reacting $1,3 \mathrm{~b}$-glucanase fruit allergens as a molecular basis for the latex-fruit syndrome. Mol Immunol 2009: 46; 1595-604.

14. Wagner $\$$, Breiteneder $H$. Hevea brasiliensis latex allergens: current panel and clinical relevance. Int Arch Allergy Immunol 2005: 136: 90-7.

15. Huecas $\$$, Villalba $M$, Rodriguez $R$. Ole e 9 , a major olive pollen allergen is a 1,3-b-glucanase. J Biol Chem 2001: 276: 27959-66.

16. Yagami T, Osuma $H$, Koumo $M$, Haishima $Y$, Nakamura A, Irezawa Z. Significance of carbohydrate epipotes in a latex allergen with b-1,3-glucanase activity. Int Arch Allergy Immunol 2002: 129: 27-37.

17. Yagami T, Sato M, Nakamura A, et al. Plant defense-related enzymes as latex antigens. J Allergy Clin Immunol 1998: 101: 379-85.

18. Palomares $O$, Villalba M, Quiralte J, Polo F, Rodriguez R, 1,3-b-glucanases as candidates in latex-pollen-vegetable food crossreactivity. Clin Exp Allergy 2005: 35: 34551.

19. Barber D, De La Torre F, Feo F, et al. Understanding patient sensitization profiles in complex pollen areas: a molecular epidemiological study. Allergy 2008: 63: 1550-8.
20. Leone $\mathrm{P}$, Menu-Bouaouiche L, Peumans WJ, et al. Resolution of the structure of the allergenic and antifungal banana fruit thaumatin-like protein at 1.7-A. Biochimie 2006: 88: 45-52.

21. Breiteneder $H$. Thaumatin -like proteins- a new family of pollen and fruit allergens. Allergy 2004: 59: 479-81.

22. Gavrovic-Jankulovic M, Cirkovic T, Vuckovic $O$, et al. Isolation and biochemical characterization of a thaumatin-like kiwi allergen. J Allergy Clin Immunol 2002: 110; 805-10.

23. Palacin A, Rodriguez $J$, Blanco $C$, et al. Immunoglobulin $E$ recognition patterns to purifled kiwifnit (Actinidinia deliciosa) allergens in patients sensitized to kiwi with different clinical symptoms. Clin Exp Allergy 2008: 38: 1220-8.

24. Oberhuber $C_{1}$ Ma Y, Marsh J, et al. Purification and characterization of relevant natural and recombinant apple allergens. Mol Nutr Food Res 2008: 52 (Suppl. 2): S20B-19.

25. Asero R, Monsalve R, Barber D. Profilin sensitization detected in the office by skin prick test: a study of prevalence and clinical relevance of profilin as a plant food allergen. Clin Exp Allergy 2008: 38: 1033-7.

26. Salcedo G, Sanchez-Monge R, Barber D, Diaz-Perales A. Plant non-specific lipid transfer proteins: an interface between plant defence and human allergy. Biochim Biophys Acta 2007: 1771: 781-91.

27. Anliker MD, Reindl J, Vieths S, Wuthrich $B$. To Allergy caused by ingestion of persimmon (Diospyros kaki): detection of specific $\lg E$ and cross-reactivity to profilin and carbohydrate determinants. I Allergy Clin Immunol 2001: 107: 718-23.

28. Bradford MM. A rapid and sensitive method for the quantitation of microgram quantities of proteins utilizing the principle of protein-dye binding. Anal Biochem 1976: 72: 248-54.

29. Diaz-Perales A, Blanco $C$, Sanchez-Monge R, Varela J, Carrillo $T$, Salcedo G. Analysis of avocado allergen (Pers a 1) lgE-binding peptides generated by simulated gastric fluid digestion. I Allergy Clin Immunol 2003: 112: 1002-7.

30. Diaz-Parales A, Sanz ML, Garcia-Casado G, et al. Recombinant and natural Pru p 3 , a major peach allergen, show equivalent immunological reactivity: a new tool for diagnosis of fruit allergy. $J$ Allergy Clin Immunol 2003: 111: 628-33.

31. Laemmli UK, Cleavage of structural proteins during the assembly of the head of bacteriophage T4. Nature 1970: 227: 680-5.
32. Faye L, Gomord V, Fitchette-Laine AC, Chrispeels MJ. Affinity purification of antibodies specific for Asn-linked glycans containing alpha 1-3 fucose or beta 1-2 xylose. Anal Biochem 1993: 209: 104-8.

33. Sub-Committee on Skin Tests of the Euro pean Academy of Allergology and Clinical Immunology. Skin tests used in type I allergy testing. Position paper. Allergy 1989: 44 (Suppl. 10): 1-59.

34. Burney $P$, Summers $C$, Chinn $S$, Hooper R, Van Ree $R_{d}$ Lidholm J. Prevalence and distribution of sensitization to foods in the European Community Respiratory Health Survey: a EuroPrevall analysis. Allergy 2010: 65: 1182-8.

35. Altmann F. The role of protein glycosylation in allergy. Int Arch Allergy Immunol 2007: 142: 99-115.

36. Ahrazem O, Ibanez MD, Lopez-Torrejon $G$ et al. Orange germin-like glycoprotein Cit s 1: an equivocal allergen. Int Arch Allergy Immunol 2006: 139: 96-103.

37. Fernandez-Rivas M, Bolhaar S, GonzalezMancebo $E$, et al. Apple allergy across Europe: how allergen sensitization profiles determine the clinical expression of allergies to plant foods. J Allergy Clin Immunol 2006 : 118: 481-8.

38. Bublin M, Pfister M, Radauer C, et al. Component-resolved diagnosis of kiwifruit allergy with purifled natural and recombinant kiwifruit allergens. J Allergy Clin Immunol 2010: 125: 687-94.

39. Palacin A, Tordesillas L, Gamboa P, et al. Characterization of peach thaumatin-like proteins and their identification as major peach allergens. Clin Exp Allergy 2010: 40: 1422-30.

40. Fernandez-Rivas M, Gonzalez-Mancebo $E_{\text {, }}$ Rodriguez-Perez $R$, et al. Clinically relevant peach allergy is related to peach lipid transfer protein, Pru p 3, in the Spanish population. J Allergy Clin Immunol 2003: 112: 789-95.

41. Asero R, Antonicelli $L_{d}$ Arena $A$, et al. EpidemAAITO: features of food allergy in Italian adults attending allergy clinics: a multi-centre study. Clin Exp Allergy 2009: 39: 547-55.

42. Asero R, Mistrello G, Roncarolo D, et al. Immunological cross-reactivity between lipid transfer proteins from botanically unrelated plant-derived foods: a clinical study. Allergy 2002: 57: 900-6.

43. Asero R, Mistrello G, Roncarolo D, Amato $\$$. Detection of some safe plant-derived foods for LTP-allergic patients. Int Arch Allergy Immunol 2007: 144: 57-63. 